
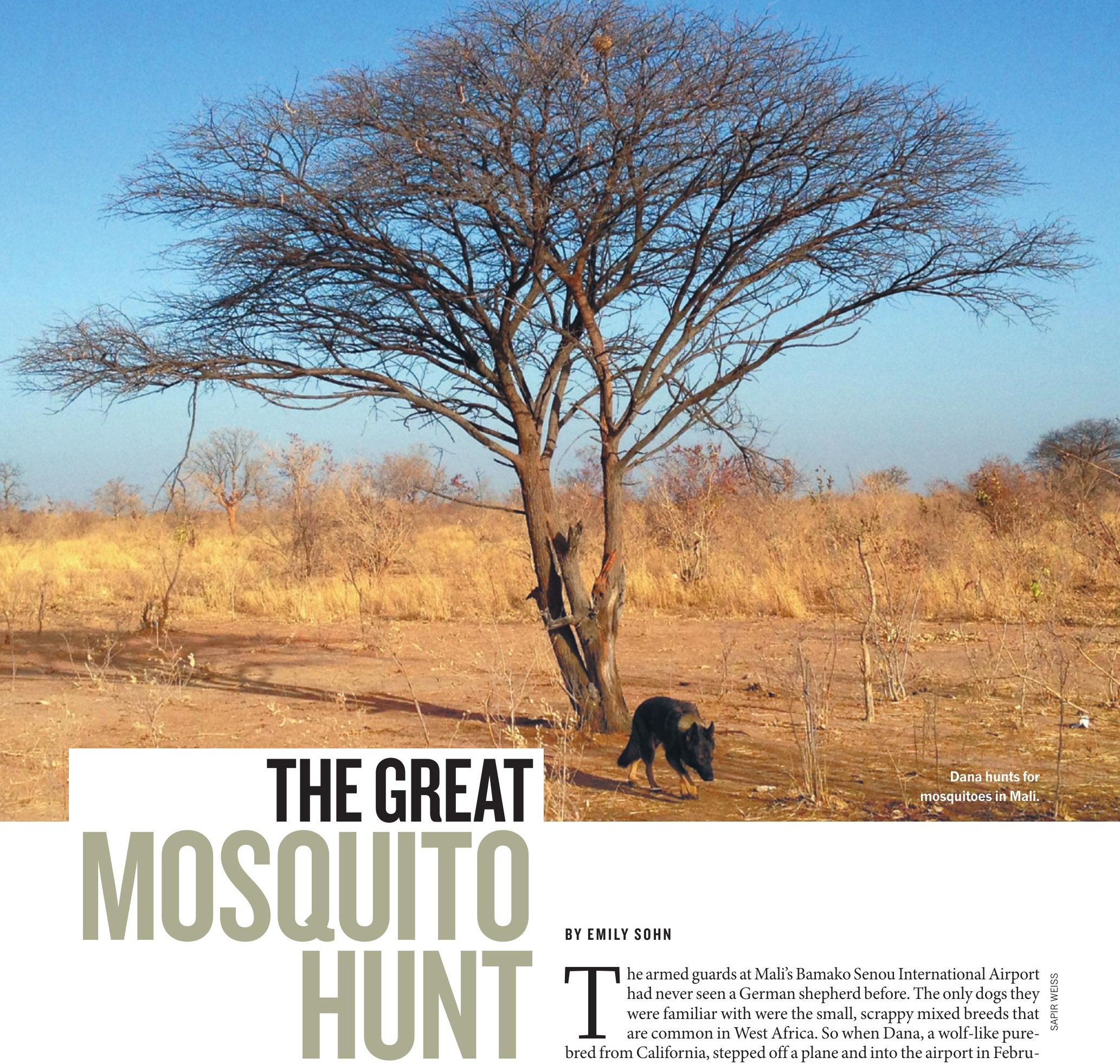

BY EMILY SOHN

From dogs to balloons, researchers are using unorthodox ways to find out where malaria vectors hide during a long dry season. he armed guards at Mali's Bamako Senou International Airport had never seen a German shepherd before. The only dogs they were familiar with were the small, scrappy mixed breeds that are common in West Africa. So when Dana, a wolf-like purebred from California, stepped off a plane and into the airport in February 2012, eight soldiers surrounded her and her trainer Sapir Weiss, guns raised.

Weiss, who once trained antiterrorism dogs for the Israeli army, was eager to get Dana outside after 36 hours of bladder-straining international travel that included a seven-hour stopover in Paris. But the soldiers thought the dog's service vest was a suicide bomb. They ordered Weiss to take it off. They demanded to know where Dana's crate was. "Where's the box?" they yelled. "Where's the box?"

To the guards, and most people in Mali, it was inconceivable that a dog could be trained to travel in economy without a crate. Equally improbable was what Dana had come to Mali to do: sniff out mosquitoes to help eradicate malaria.

Dana is part of an ongoing effort to solve a perplexing mystery. Every year, a swathe of the African Sahel region from Senegal to Sudan experiences an extreme dry season that lasts for up to eight months. As surface waters disappear, mosquitoes can no longer reproduce because their 
eggs and larvae must remain wet to survive. The number of mosquitoes buzzing around crashes to near zero.

But when the rains come, adult bloodsuckers appear in explosive numbers in as little as three days - a timeline that is hard to square with the fact that it takes at least eight days for these mosquitoes to grow from egg to adult.

The pattern suggests that adult mosquitoes hide somewhere to wait out the dry season, and that possibility points to a tantalizing plan of attack. Every year, malaria makes hundreds of millions of people ill and kills more than half a million, mostly children in Africa. If scientists could figure out where the mosquitoes go when conditions become inhospitable during dry seasons, they might be able to wipe out the insects - and with them the disease they carry - at a point when they are likely to be easy targets.

For decades, the hunt for mosquito hideouts has both enticed and plagued scientists, who have run up against a long list of frustrations. Among those refusing to give up is Tovi Lehmann, a research entomologist at the US National Institute of Health's Laboratory of Malaria and Vector Research in Rockville, Maryland, who, along with dozens of team members in both the United States and Africa, has spent six years and about US $\$ 700,000$ trying to find the elusive insects with every method he can think of, including dogs such as Dana.

The potential pay-off is worth the massive effort, he says. "You could imagine visiting villages for less than half a day, targeting those putative sites and basically cutting malaria transmission to the point where it would be trivial."

\section{ELUSIVE QUARRY}

It takes 4 hours to drive from the Malian capital, Bamako, to Thierola, an off-the-grid village of about 300 residents and 120 buildings, made mostly from mud bricks and with thatched or mud roofs.

During the wet season, from May or June through to October or November, half a metre of rain falls on the region. Bushes turn green. Millet, maize (corn), peanuts and other crops grow. And mosquitoes arrive. Fast. Lehmann's team has seen mosquito numbers in Thierola surge tenfold within five days of the rain's start ${ }^{1}$.

Entomologists have come up with two explanations for how mosquito populations can swell so rapidly before they have had a chance to reproduce. One possibility is long-distance migration on high-elevation winds. Alternatively, the insects might spend the dry season in aestivation, a unique type of dormancy that occurs in some animals that need to survive long dry seasons.

Lehmann's group found an early clue that aestivation might be the answer. At the end of the rainy season in late October 2008, the team anaesthetized almost 7,000 mosquitoes, marked them with poster paint and released them. During collections the next May, they were amazed to find a live adult female with the telltale marks, despite the fact that Anopheles gambiae (the complex of species that transmit malaria most efficiently in the Sahel) are known to live for 30 days at most.

Although aestivation seems a likely scenario, the process has been difficult for biologists to explain. In temperate regions, mosquito species are known to go dormant to survive cold winters, which makes sense because insect metabolisms naturally slow when temperatures drop. Sub-Saharan Africa, on the other hand, is always hot, so it is harder to understand how mosquitoes could slow their metabolism there. The insects must also somehow resist desiccation.

Attempts to induce aestivation in mosquitoes have produced little more than circumstantial and anecdotal evidence. Studies in the 1940s, for instance, tried to replicate natural conditions in the lab but failed to get female mosquitoes to go dormant, according to Douglas Norris, a medical entomologist at the Johns Hopkins Bloomberg School of Public Health in Baltimore, Maryland. A letter ${ }^{2}$ published in Nature in 1968 described mosquitoes that managed to survive for almost seven months in an insectary in hot, dry Sudan, but those results were never replicated.

Genetic studies could also help to shed light on

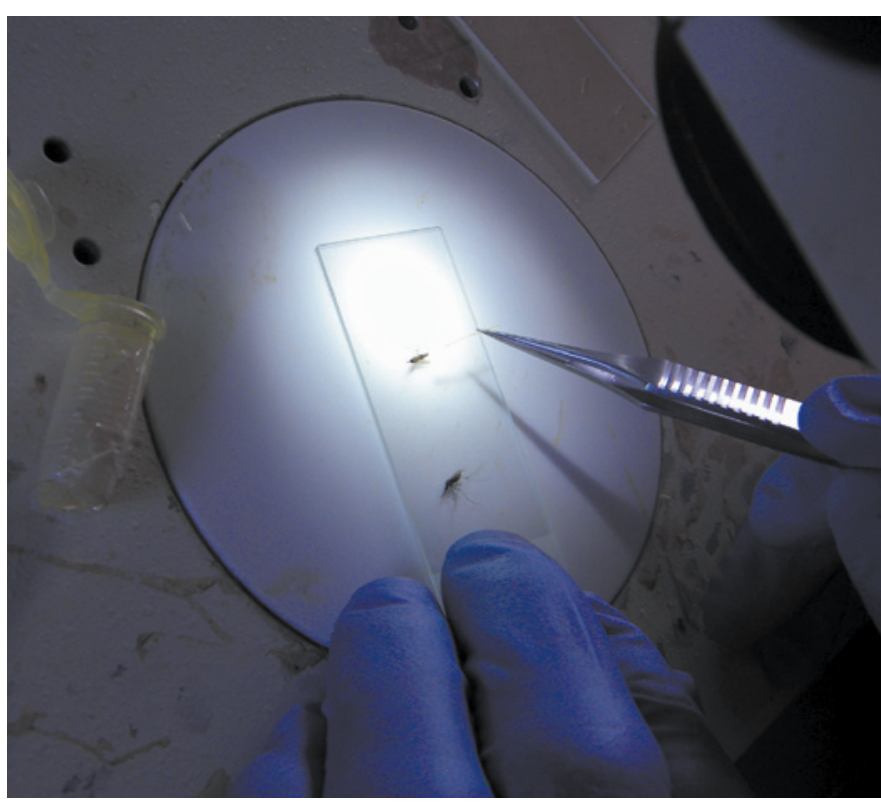

To help dogs to pick up the scent, researchers have been attaching strings doused in vetiver oil to mosquitoes.

the aestivation hypothesis. When Norris and his colleagues looked at genetic markers from one wet season to the next in a village in Mali in the late 1990s, they found that at least 5,000 females had to survive the dry season to found a new population ${ }^{3}$. And Martin Donnelly at the Liverpool School of Tropical Medicine, UK, and his colleagues have been comparing the genomes of Anopheles mosquitoes from across Africa. If genomes remain consistent from one set of rains to the next, that would show even more strongly that many mosquitoes endure the dry season, as opposed to being replaced each year by a population of migrants.

The discovery of the painted female as the rains swept into Thierola showed that a wild mosquito could survive the dry season - the equivalent of a human living for 700 years, Lehmann says. Norris is building field enclosures in southern Gambia for his own studies of mosquito biology and may eventually make try to demonstrate aestivation in that environment. "This is something we believe happens, but nobody has been able to prove it other than Tovi's one mosquito."

So for the next couple of years, as the rains again approached, the team set up nets around suspected refuges, determined to catch mosquitoes as they first emerged. "We thought in a year or two, we were going to be able to find where they hide," Lehmann says. "Everything looked within reach, and it looked very simple."

Despite around-the-clock monitoring, and even a manufactured rainstorm created by a water-filled truck to lure the mosquitoes out of hiding, the insects remained elusive. Potential hiding spots seemed overwhelming, numbering in the hundreds within just 500 metres of the village, making it impossible to put nets and cages around them all. The hunt, it turned out, would not be so simple after all.

\section{ON THE SCENT}

Lehmann's project was not the first to misfire. About 15 years ago, Frédéric Simard, a medical entomologist at the Institute of Research for Development, a government institution in Montpellier, France, went on a similar quest in dry-season Senegal. He set up traps around as many potential hiding spots as he could think of, indoors and out, including barns, silos, water-storage containers, wells, tree stumps, tree trunks and cracks in the bottom of dried ponds - to no avail. "There was no evidence for resting mosquitoes anywhere despite huge efforts," he says. "This is basically just like looking for a needle in a haystack."

A group from the University of Miami in Coral Gables, Florida, has scattered tent-like cages around a village in Kenya. And a team based at Hebrew University in Israel is looking for aestivating mosquitoes in 


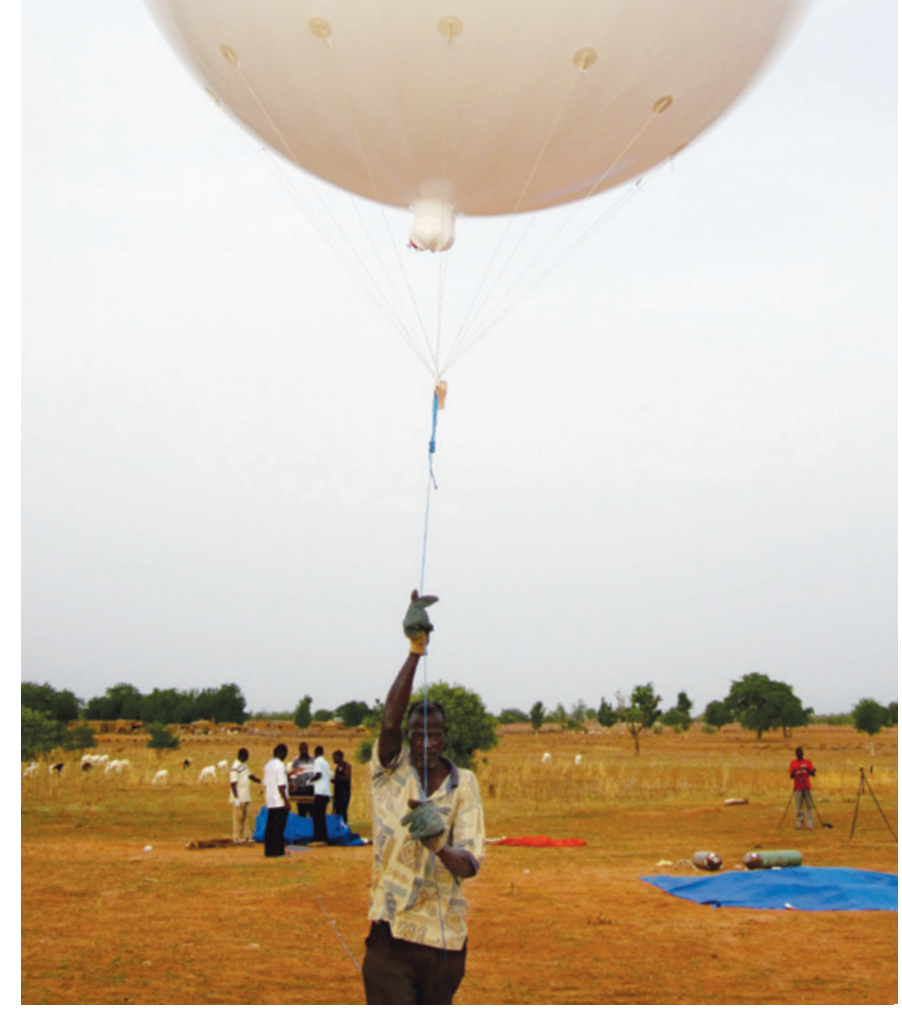

Helium balloons equipped with traps are being used to find any mosquitoes travelling on high-altitude winds.

wet hideouts outside villages in Mali by, among other methods, flooding animal burrows with water to try to flush out the insects. Neither team has found anything conclusive.

Given so many failed attempts before him, Lehmann decided that he would have to come up with a more targeted strategy. When he heard about dogs that could sniff out bedbugs, he latched on to the idea, despite some potentially major challenges. For instance, unlike bedbugs, mosquitoes fly, making them wily and harder to track. And whereas bedbugs emit distinctive pheromones, mosquitoes have no natural scent.

First, he set out to find a way to give mosquitoes an odour. Months of experimenting finally led to vetiver oil, a perfume ingredient derived from an eastern Asian weed grass with an earthy, woodsy smell. Vetiver is not native to Africa, so it would not confuse a dog's nose. It is not toxic or foul smelling, so researchers would not baulk at working with it. And it is stable enough to last for a couple of weeks, long enough to use in experiments. The researchers found that spraying the mosquitoes with vetiver killed the insects, so they soaked tiny bits of string in the scent, then glued the strings onto the bellies of anaesthetized mosquitoes. When they woke, the mosquitoes could still fly, even with the extra weight.

In the meantime, Lehmann called Weiss, who jumped at the opportunity to train a dog to track scented mosquitoes, even though several trainers before him had rejected the idea as impossible. On the sunny lawn of his Olivet Kennel and Dog Training Resort in Santa Rosa, California, Weiss got to work with Dana, allowing her to sniff six cardboard boxes. When she came to the one scented with vetiver, she got her favourite reward: a tennis ball. After a year of training, Dana could find 1-centimetre-long scented strings with $97 \%$ accuracy, even when they were put in vials and placed in open holes 20 centimetres deep.

To see whether she would perform as well in Africa, Weiss and Dana flew to Mali in early 2012. Dana sat with Weiss inside the plane so that she would not overheat in the cargo hold. The airport stand-off nearly derailed the whole project, and once they made it to Thierola, Weiss had to retrain Dana because of the extreme heat. Dogs must pant to stay cool, but they can't do that and sniff at the same time. With temperatures near $50^{\circ} \mathrm{C}$, Dana needed to learn to stop and cool off every five minutes.

Over the course of a month, Dana found scented strings hidden in natural holes again and again. She also found mosquitoes that had been marked with scented strings and released days before, including one under a pile of clothes in a laundry basket. The 30 or so Malians in the search crew were flabbergasted. "They were just jumping up and down," Weiss says. "My status got elevated. They thought I was a shaman because I could talk to a dog and the dog would listen to me."

The hope was to get the scented mosquitoes to lead the researchers to their secret lairs. But Dana ran out of time, returning home with Weiss just before a coup swept Mali. Lehmann departed soon after, leaving the mosquito-hunting project in the hands of Adama Dao, an entomologist at the University of Bamako's Malaria Research and Training Centre, who had been leading the Mali-based portion of the team.

In August 2012, two Malian handlers and their dogs travelled to Santa Rosa to learn both the mosquito-sniffing task and how to build a close human-dog relationship. One handler was a physician, the other had a biology degree. Both had been working with Dao and Lehmann for two years on other search strategies, and they were enthusiastic about what they had seen Weiss and Dana do.

The Malian-led dry-season dog work, which continued until December 2013, turned up about nine suspected hiding places, Dao says. Both dogs had independently led the team to the same small tree holes, open holes in the ground near trees and old termite mounds, mostly within about 1.5 kilometres of the village. Nets were set up around the potential shelters at the end of the dry season. But like many who came before them, the researchers found no hordes of aestivating mosquitoes.

\section{A WIDER NET}

This month, Lehmann returned to Thierola for the first time in more than two years, armed with some new ideas. He has erected huge nets around the community's wells, for instance. And he has some moreunorthodox plans. Given that other insects might use similar strategies to endure the harsh dry season in the Sahel, he wants to find a larger sentinel species that can be fitted with a radio transmitter and potentially lead researchers to hiding mosquitoes. He also wonders if they could find a marker - such as fungal DNA, trace chemicals or cells from plants or animals - that they could put in suspected shelters. Any mosquitoes emerging from those places would then carry lingering tags that would lead researchers straight to the source, if they can catch the escapees quickly enough.

Meanwhile, the search is moving out and up - to, among other places, a set of caverns about 30 kilometres away and into helium balloons equipped to trap any mosquitoes travelling in by wind. Preliminary studies during the wet season have located a few A. gambiae flying as high as 160 metres above the ground, even though there is nothing for them to eat up there. It is now starting to look as though one of the three species of mosquito that transmit malaria in the region aestivates, and the other two migrate, says Lehmann.

So far, Lehmann and his team have published nine papers on the hunt and have three more in the works. As they continue their efforts in the field, other malaria researchers are cheering them on. "Any time you can find a stage where mosquito numbers are very low and they are maybe congregating in one spot, you could really have a big impact," says Gregory Lanzaro, an entomologist at the University of California, Davis, who studies the population genetics of A. gambiae in Africa. "There's always hope. When you work on things like malaria, you can't be a pessimistic person. Otherwise, you'd stay home."

Lehmann and Dao remain optimistic that they will eventually find the elusive mosquito dens, where a few low-cost squirts of insecticide could save so many lives. Every setback, they say, provides new information. "We have never been disappointed and we will remain hopeful," says Dao. "As long as we have resources, we will reach our goal." -

\section{Emily Sohn is a freelance journalist based in Minneapolis.}

1. Lehmann, T. et al. Am. J. Trop. Med. Hyg. 83, 601-606 (2010).

2. Omer, S. M. \& Cloudsley-Thompson, J. L. Nature 217, 879-880 (1968)

3. Taylor, C. et al. Genetics 157, 743-750 (2001). 